\title{
miR-145 inhibits proliferation and migration of breast cancer cells by directly or indirectly regulating TGF- $\beta 1$ expression
}

\author{
YANLING DING $^{1 *}$, CHUNFU ZHANG $^{2 *}$, JIAHUI ZHANG $^{1}$, NANNAN ZHANG $^{1}$, TAO LI $^{1}$, \\ JIE FANG $^{3}$, YI ZHANG ${ }^{1}$, FEIYANG ZUO ${ }^{1}$, ZEHUA TAO $^{1}$, SHENGNAN TANG $^{1}$, \\ WEI ZHU ${ }^{1}$, HUABIAO CHEN ${ }^{1,4}$ and XIAOCHUN SUN ${ }^{1}$
}

${ }^{1}$ School of Medicine, Jiangsu University, Zhenjiang, Jiangsu 212013; ${ }^{2}$ The Second People's Hospital of Kunshan, Kunshan, Jiangsu 215300; ${ }^{3}$ Affiliated Hospital of Jiangsu University, Zhenjiang, Jiangsu 212001, P.R. China; ${ }^{4}$ Vaccine and Immunotherapy Center, Massachusetts General Hospital and Harvard Medical School, Boston, MA 02114, USA

Received September 15, 2016; Accepted March 6, 2017

DOI: 10.3892/ijo.2017.3945

\begin{abstract}
Studies have demonstrated low expression of miR-145 associated with cell proliferation and migration in a wide variety of tumors. Here, we studied the expression of miR-145 in relation to the occurrence and development of breast cancer. Total RNA from breast cancer tissue and corresponding adjacent normal tissue was extracted and used to detect miR-145 expression by quantitative real-time polymerase chain reaction (qRT-PCR). We also transfected breast cancer cells with hsa-miR-145 mimics, hsa-miR-145 inhibitor, mimics negative control (mimics NC) or inhibitor negative control (inhibitor NC). Cell proliferation was analyzed by colony formation assays and methyl thiazolyl tetrazolium assays. Cell proliferation in breast cancer cells was decreased after overexpression of miR-145 and increased following miR-145 suppression. Cell migration and invasion were assessed using Transwell and wound healing assays, respectively, and were also decreased after overexpression of miR-145 and increased after miR-145 suppression in breast cancer cells. Finally, western blot assays showed that overexpression of miR-145 inhibited expression of transforming growth factor- $\beta 1$ (TGF- $\beta 1$ ). Collectively, these data suggest that miR-145 may inhibit TGF- $\beta 1$ protein expression which may in turn contribute to tumor formation.
\end{abstract}

Correspondence to: Dr Xiaochun Sun, School of Medical Science and Laboratory Medicine, Jiangsu University, Zhenjiang, Jiangsu 212013, P.R. China

E-mail: xiaochun@ujs.edu.cn

Professor Huabiao Chen, Vaccine and Immunotherapy Center, Massachusetts General Hospital and Harvard Medical School, Boston, MA 02114, USA

E-mail: huabiao.chen@mgh.harvard.edu

*Contributed equally

Key words: breast cancer, miRNA, miR-145, proliferation, migration, TGF- $\beta 1$

\section{Introduction}

Breast cancer is one of the most frequently diagnosed malignant cancers in women worldwide (1). Breast cancer is the second leading cause of cancer-related deaths among females, with a yearly toll of more than 40,000 deaths in the United States alone (2). Furthermore, the number of cases is increasing, which represents a serious threat to women's health and their quality of life. Therefore, research in the diagnosis and treatment of breast cancer is very important (3).

MicroRNAs (miRNAs) play important roles in cancers (4). miRNAs form a class of small non-coding RNAs (5) which function by binding to the 3 ' terminal untranslated region of targeted mRNAs to inhibit their translation (6). Furthermore, miRNAs are important for regulating various biological processes including proliferation, migration and inhibition of apoptosis (7). miR-145 is a microRNA which has been widely studied in cancer and has been shown to be expressed at low levels in a wide variety of tumors, including bladder cancer (8), colorectal cancer (9), and lung cancer (10).

In this study, we examined the role of miR-145 in human breast cancer. Expression levels of miR-145 in breast cancer tissue and adjacent normal tissue were first analyzed using quantitative real-time polymerase chain reaction (qRT-PCR) (3). We then transfected breast cancer cells with hsa-miR-145 mimics, hsa-miR-145 inhibitor, mimics negative control (mimics NC) and inhibitor negative control (inhibitor NC). Cell proliferation was analyzed by colony formation assay and MTT cell proliferation assay. Cell migration was assessed using Transwell and wound-healing assays. Previous studies indicated that transforming growth factor- $\beta 1$ (TGF- $\beta 1$ ) played an important role in growth and metastasis of breast cancer cells (11). To detect the relationship between TGF- $\beta 1$ and miR-145, we used western blot analysis to analyze protein expression of TGF- $\beta 1$.

\section{Materials and methods}

Breast cancer and normal tissues. The ethics committee of Jiangsu University (Zhenjiang, Jiangsu, China) approved all aspects of this study. Documented informed consent 
Table I. Sequences of miR-145 mimics, miR-145 inhibitor and negative controls.

\begin{tabular}{ll}
\hline Name & \multicolumn{1}{c}{ Sequence } \\
\hline $\begin{array}{l}\text { Hsa-miR-145 mimic } \\
\text { Sense }\end{array}$ & 5'-GUCCAGUUUUCCCAGGAAUCCCU-3' \\
Antisense & 5'-GGAUUCCUGGGAAAACUGGACUU-3' \\
Mimic-negative & \\
control & \\
Sense & 5'-UUCUUCGAACGUGUCACGUTT-3' \\
Antisense & 5'-ACGUGACACGUUCGGAGAATT-3' \\
Hsa-miR-145 & 5'-AGGGAUUCCUGGGAAAACUGGAC-3' \\
inhibitor & \\
Inhibitor negative & 5'-CAGUACUUUUGUGUAGUACAA-3' \\
control & \\
\hline
\end{tabular}

was obtained from all subjects. Breast cancer tissues and corresponding adjacent normal tissues were obtained from the Department of Surgery, the Second People's Hospital of Kunshan, China. Cancer status was histologically confirmed, and all tissues were immediately stored at $-80^{\circ} \mathrm{C}$.

Cell culture. Breast cancer cells (MCF-7 and MDA-MB 231) were provided from Nanjing University and grown in DMEM (Gibco, Carlsbad, CA, USA) containing 10\% fetal bovine serum (ExCell Biology, Shanghai, China) at $37^{\circ} \mathrm{C}$ in a humidified chamber.

Cell transfection. Breast cancer cells were seeded in 6-well plates. After $24 \mathrm{~h}$, the cells were transfected with $100 \mathrm{nM}$ of miR-145 mimics, miR-145 inhibitor, mimics NC or inhibitor NC (provided by GenePharma, Shanghai, China), using Lipofectamine-2000 (Invitrogen, Carlsbad, CA, USA) according to the manufacturer's protocol. The sequences are listed in Table I.

Quantitative real-time PCR. Total cellular RNA was isolated from tissue samples and cells using TRIzol reagent (Invitrogen) according to the manufacturer's protocol. RNA $(1 \mu \mathrm{g})$ was reverse transcribed into cDNA using reverse transcriptase (GenePharma). The expression levels of miR-145 were evaluated by quantitative real-time PCR performed using a SYBR green-containing PCR kit (GenePharma). A CFX-96 real-time fluorescence thermal cycler (Bio-Rad, Hercules, CA, USA) was used for quantitative miRNA and mRNA detection. U6 snRNA was used for normalization of miR-145 expression levels and GAPDH was used for normalization of TGF- $\beta 1$ mRNA expression levels. Primer sequences are listed in Table II. miR-145 and TGF- $\beta 1 \mathrm{mRNA}$ expression levels were calculated using the $2^{-\Delta C t}$ method relative to U6 snRNA and GAPDH.

Cell proliferation assay. The effect of miR-145 on proliferation was measured using Thiazolyl Blue Tetrazolium Bromide-MTT (Amresco, Solon, OH, USA). Briefly, 4x10 $0^{3}$ cells transfected with miR-145 mimics, miR-145 inhibitor, mimics NC or
Table II. Specific primers for target and control genes.

\begin{tabular}{lc}
\hline Name & \multicolumn{1}{c}{ Sequence } \\
\hline miR-145 & F: 5'-CAGTCTTGTCCAGTTTTCCCAG-3' \\
& R: 5'-TATGCTTGTTCTCGTCTCTGTGTC-3' \\
U6snRNA & F: 5'-ATTGGAACGATACAGAGAAGATT-3' \\
RG: 5'-GGAACGCTTCACGAATTTG-3' & F: 5'-GTACCTGAACCCGTGTTGCT-3' \\
& R: 5'-GTATCGCCAGGAATTGTTGC-3' \\
GAPDH & F: 5'-GAAGGTGAAGGTCGGAGTC-3' \\
& R: 5'-GAAGATGGTGATGGGATTTC-3 \\
\hline
\end{tabular}

F, forward; $R$, reverse.

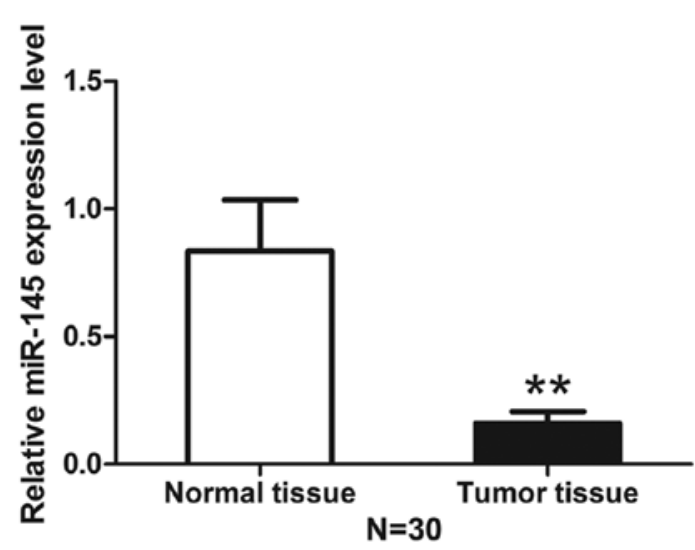

Figure 1. miR-145 levels in breast cancer tissues. We analyzed the RNA expression of miR-145 by qRT-PCR. The expression level of miR-145 was decreased in breast cancer tissues compared to adjacent normal tissues. The graph represents the mean of $2^{-\triangle \mathrm{Ct}}$ values $\pm \mathrm{SD}$. SD, standard deviation, ${ }^{* * *} \mathrm{P}<0.01$.

inhibitor NC were plated in 96-well plates. MTT reagent was added to each well 24, 48 and $72 \mathrm{~h}$ after seeding. After $4 \mathrm{~h}$ incubation, the reagent was removed and dimethyl sulfoxide was added to each well. The absorbance value in each well was measured with an FLx800 Fluorescence Microplate Reader (BioTek, Winooski, VT, USA) at $490 \mathrm{~nm}$.

Colony formation assay. Breast cancer cells transfected with miR-145 mimics, miR-145 inhibitor, mimics NC or inhibitor $\mathrm{NC}$ were seeded into six-well plates and incubated for 12 days. Colonies were fixed with formaldehyde, stained with crystal violet and counted. Assays were performed in triplicate.

Transwell invasion assay. Transwell invasion assays were performed using Transwell plates (Corning Inc., Corning, NY, USA) containing membranes with $8 \mu \mathrm{m}$ pores. Breast cancer cells were transfected with miR-145 mimics, miR-145 inhibitor, mimics NC or inhibitor NC. After 48 h, 4x10 4 cells were resuspended in $200 \mu \mathrm{l}$ serum-free medium and seeded into the upper chamber. Culture medium containing $10 \%$ fetal bovine serum was added to the lower chamber as the chemoattractant. The cells were incubated in a humidified 


\section{A \\ MDA-MB-231}

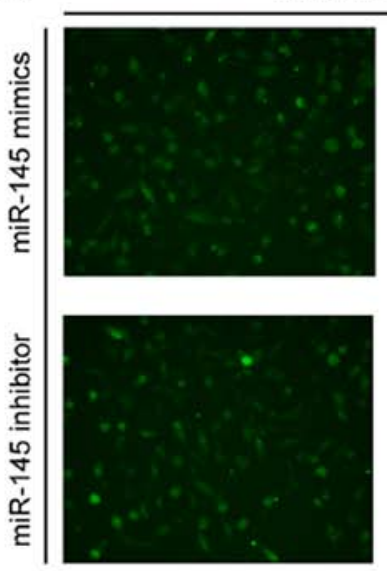

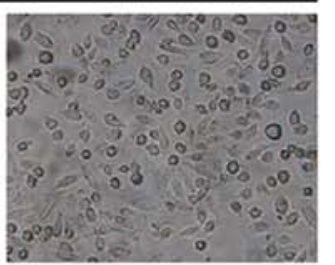

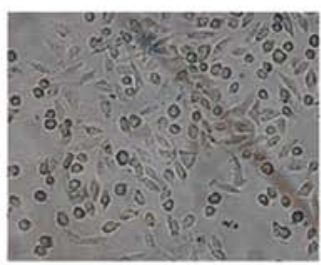

MCF-7
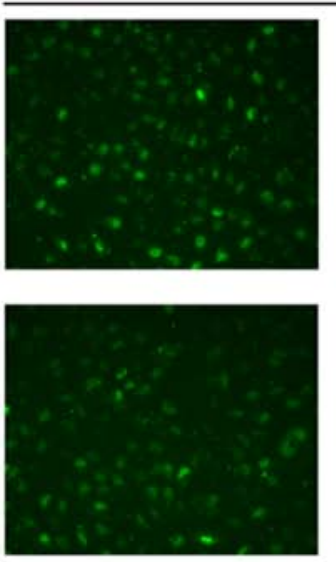
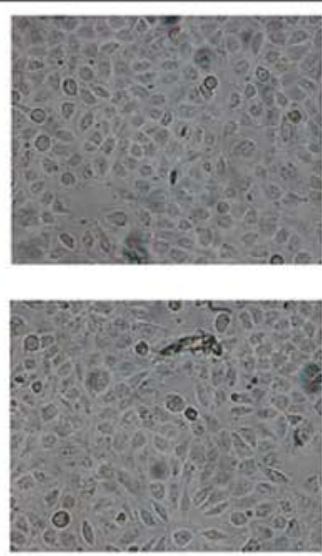

B

MDA-MB-231
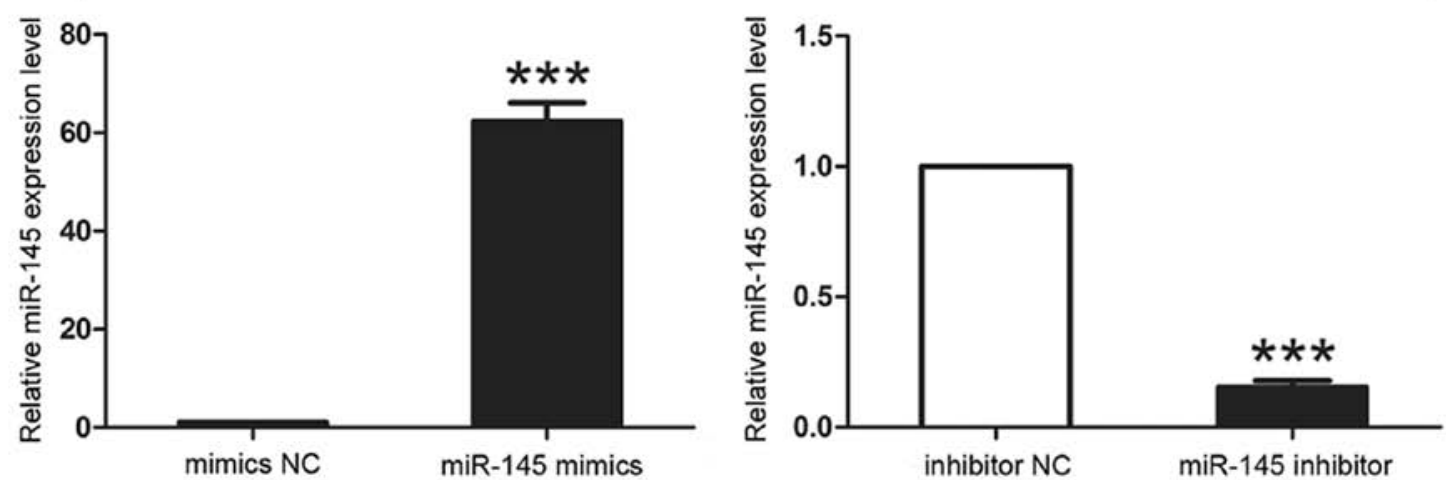

MCF-7
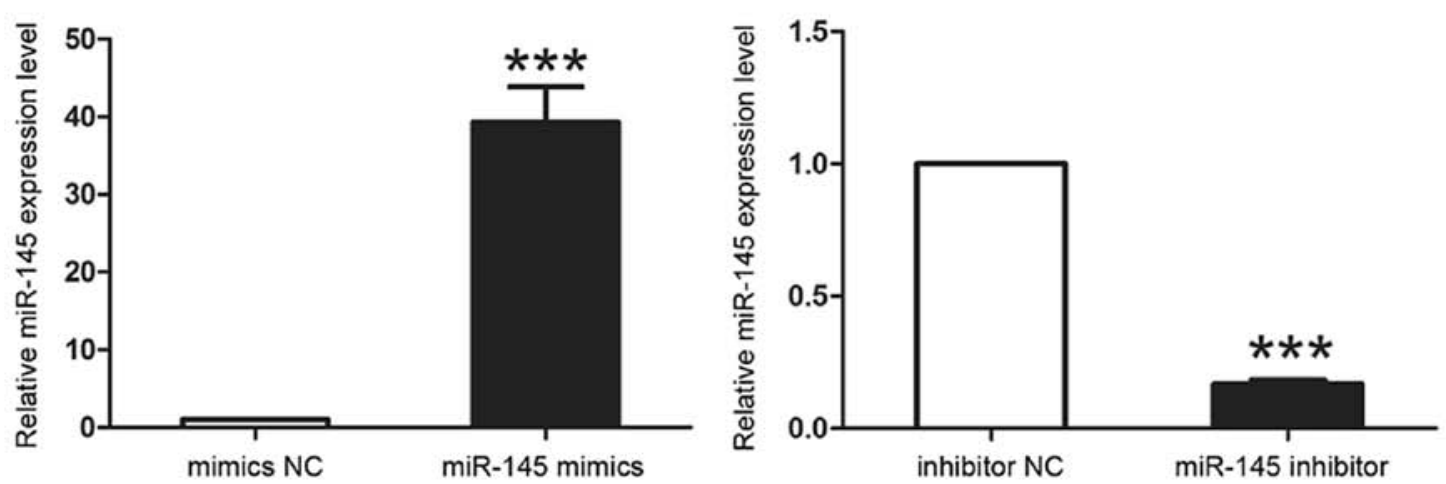

Figure 2. Transfection of miR-145 mimics and miR-145 inhibitor in breast cancer cells. We transfected miR-145 mimics or inhibitor into breast cancer cell lines (MDA-MB-231 and MCF-7) to confirm the function of miR-145. After $6 \mathrm{~h}$, we estimated the transfection efficiency by fluorescence microscopy (x200), presented as FAM-expressing cells (A, left panel) and differential interference contrast images (A, right panel). miR-145 expression was verified by real-time $\mathrm{PCR}(\mathrm{B})$. The graph represents the mean of $2^{-\Delta \mathrm{Ct}}$ values $\pm \mathrm{SD},{ }^{* * *} \mathrm{P}<0.001$.

incubator at $37^{\circ} \mathrm{C}$ for $14 \mathrm{~h}$, and cells which had migrated to the lower surface of the insert were stained and counted. Assays were performed in triplicate.

Wound scratch assay. Wound scratch assays were performed in 6-well Transwell chambers (Corning). Cells transfected with miR-145 mimics, miR-145 inhibitor, mimics $\mathrm{NC}$ or inhibitor NC were plated and grown to $100 \%$ confluence Scratches were created with sterile pipette tips. The wounds were photographed at 0 and $48 \mathrm{~h}$ and monitored following standard protocols.
Western blot analysis. We use a modified radio immunoprecipitation assay lysis buffer (Beyotime, Shanghai, China) and phenylmethanesulfonyl fluoride (Beyotime) to extract total cellular protein from cells $48 \mathrm{~h}$ after they were transfected with miR-145 mimics, miR-145 inhibitor, mimics NC or inhibitor NC. Equal amounts of protein lysates (100-150 $\mu \mathrm{g})$ were separated by $10 \%$ sodium dodecyl sulfate polyacrylamide gel electrophoresis (Beyotime) and then transferred to polyvinylidene fluoride membranes (Beyotime). The membranes were blocked with $5 \%$ nonfat milk for $2 \mathrm{~h}$ and then incubated with primary anti-TGF- $\beta 1$ (Bioworld Technology, Inc, St. Louis, 
A

MDA-MB-231
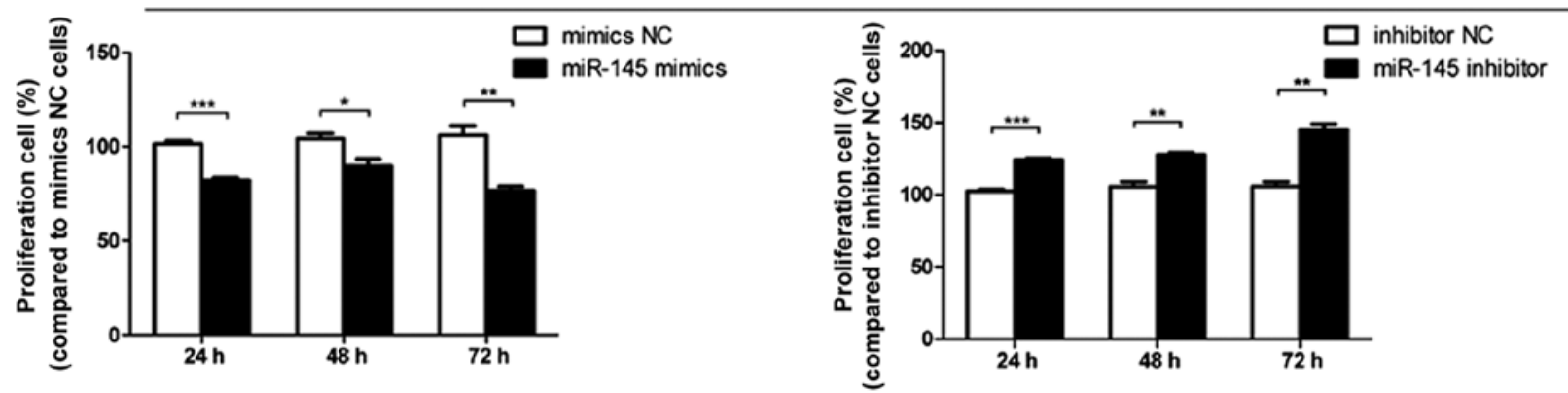

B

MCF-7
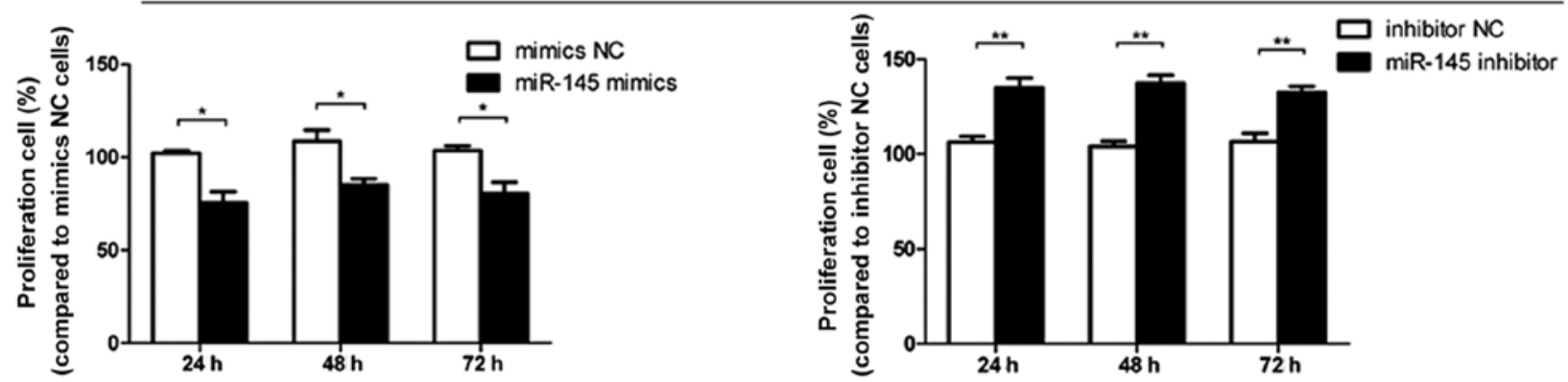

Figure 3. Cell proliferation is inhibited by miR-145. Breast cancer cell lines (MDA-MB-231 and MCF-7) were transfected with miR-145 mimics, miR-145 inhibitor, mimics NC or inhibitor NC. Cell proliferation was evaluated by MTT assays at 24, 48 and $72 \mathrm{~h}$ after transfection. The graph represents relative proliferation rates of cells transfected with miR-145 mimics (A and B, left panels) or miR-145 inhibitor (A and B, right panels) compared to their negative controls (mimics NC or inhibitor NC), shown as means $\pm \mathrm{SD},{ }^{*} \mathrm{P}<0.05,{ }^{* *} \mathrm{P}<0.01,{ }^{* * * *} \mathrm{P}<0.001$.

MN, USA, BS1361, dilution of 1:500) and anti-GAPDH (Ruiying, RLM3029, dilution of 1:1000) at $4^{\circ} \mathrm{C}$ overnight. Membranes were washed three times in TBST (Tris Buffered Saline, with Tween-20), 10 min per wash, and incubated with HRP (horseradish peroxidase)-conjugated secondary antibodies (anti-mouse or anti-rabbit IgG, Ruiying, RS0001 and RS0002, dilution of 1:2000) for $2 \mathrm{~h}$ at room temperature. Finally, immunoblots were visualized using chemiluminescence reagents (ECL, Beyotime).

Statistical analyses. Results were expressed as means \pm standard deviation (SD) using the GraphPad Prism V5.0 software program (GraphPad, San Diego, CA, USA). P-values were obtained from $\mathrm{t}$-tests for either paired or independent samples. $\mathrm{P}$-value $<0.05$ was considered to indicate a statistically significant difference.

\section{Results}

Expression level of miR-145 is decreased in breast cancer tissues compared with adjacent normal tissue. Total RNA extracted from breast cancer tissue and corresponding adjacent normal tissue was analyzed using qRT-PCR to determine the level of miR-145. The expression level of miR-145 was decreased in breast cancer tissues compared with normal adjacent tissues (Fig. 1). We then transfected miR-145 mimics or inhibitor into breast cancer cell lines (MDA-MB-231 and MCF-7) to confirm their effect on miR-145 expression. After $6 \mathrm{~h}$, we evaluated transfection efficiency by fluorescence microscopy and verified miR-145 expression levels by qRT-PCR and found that the transfection was successful (Fig. 2).
miR-145 inhibits the proliferation of breast cancer cells. Cell proliferation assays indicated that proliferation was inhibited when cells were transfected with miR-145 mimics compared with mimics NC transfection (Fig. 3). Furthermore, cell proliferation increased following transfection with miR-145 inhibitor compared with inhibitor NC transfection (Fig. 3). These data showed that miR-145 could decrease the proliferation of breast cancer cells.

miR-145 decreases colony formation of breast cancer cells. Colony formation assays showed that cell colony formation was inhibited when cells were transfected with miR-145 mimics compared with mimics NC transfection (Fig. 4). In contrast, cells transfected with miR-145 inhibitor formed more colonies than inhibitor NC-transfected cells (Fig. 4). These results showed that miR-145 could inhibit colony formation in breast cancer cells.

miR-145 influences the invasive ability of breast cancer cells. Transwell invasion assays showed that the number of membrane-penetrating cells transfected with miR-145 mimics was significantly less than the number transfected with mimics NC (Fig. 5). Moreover, the number of membrane-penetrating cells transfected with miR-145 inhibitor was significantly greater than the number of cells transfected with inhibitor NC (Fig. 5). We therefore concluded that miR-145 could inhibit breast cancer cell invasion (Fig. 5).

miR-145 decreases the migration of breast cancer cells. Wound scratch assays showed that the wound size in the miR-145-transfected group was greater at $48 \mathrm{~h}$ than that in the 
A
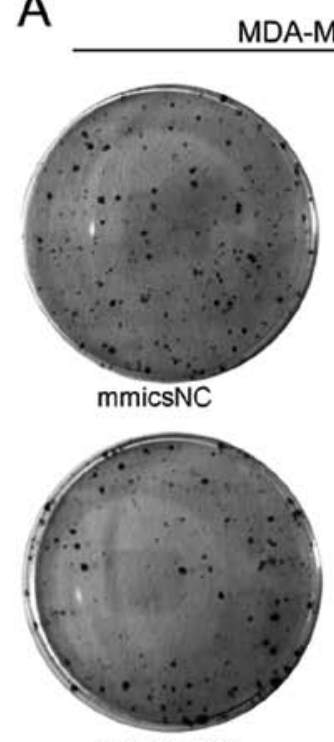

inhibitor NC

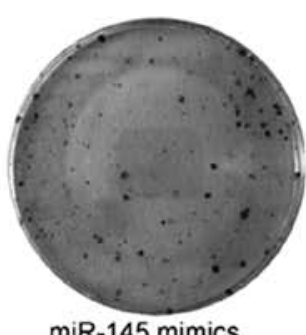

miR-145 mimics

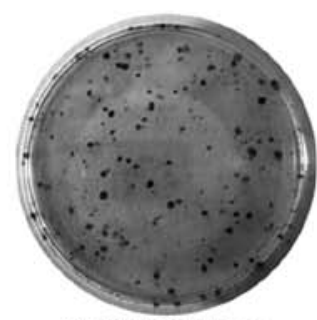

miR-145 inhibitor

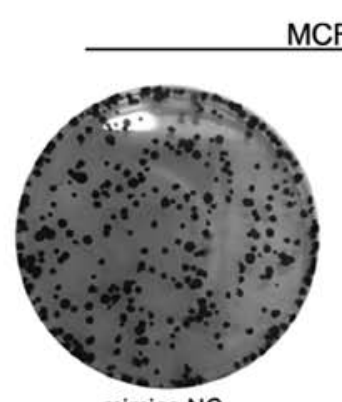

mimics NC

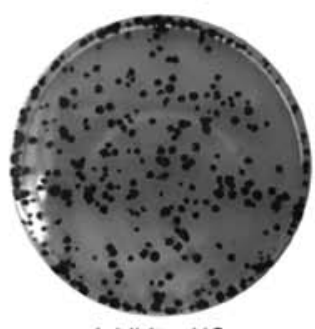

inhibitor NC
MCF-7
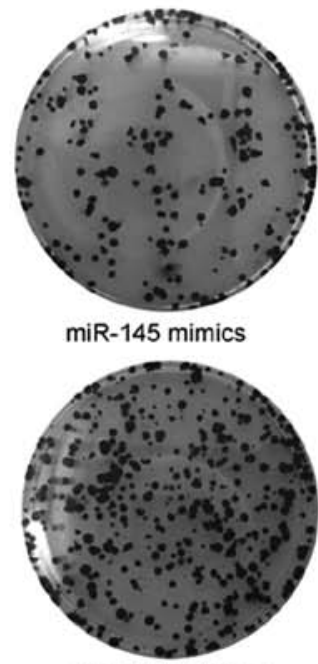

miR-145 inhibitor

B

MDA-MB-231
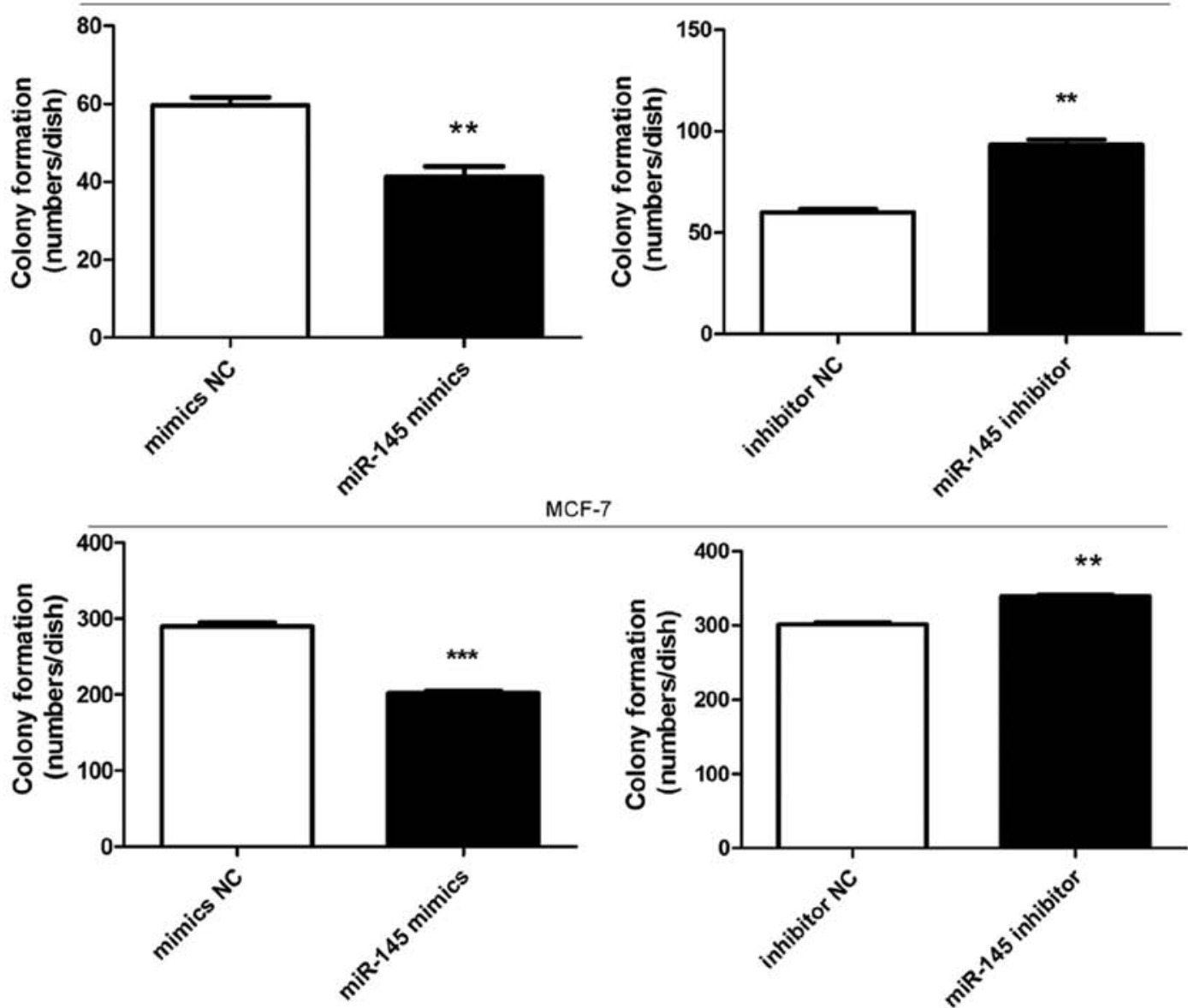

Figure 4. Cell colony formation is inhibited by miR-145. (A) Colony formation by breast cancer cell lines (MDA-MB-231 and MCF-7) was evaluated by colony formation assays at 12 days (MDA-MB-231, left panels) and 14 days (MCF-7, right panels) after transfection with miR-145 mimics, miR-145 inhibitor, mimics $\mathrm{NC}$ or inhibitor NC. (B) The graph represents the mean colony numbers \pm SD for MDA-MB-231 cells transfected with mimics and inhibitor (top panels, left and right, respectively) and similarly transfected MCF-7 cells (bottom panels). ${ }^{* *} \mathrm{P}<0.01,{ }^{* * *} \mathrm{P}<0.001$.

mimics negative control groups, indicating that cells transfected with miR-145 mimics migrated more slowly than cells transfected with mimics NC. Cells transfected with miR-145 inhibitor migrated the most rapidly of all transfected cells. Therefore, miR-145 decreased the migratory ability of breast cancer cells (Fig. 6). 
A
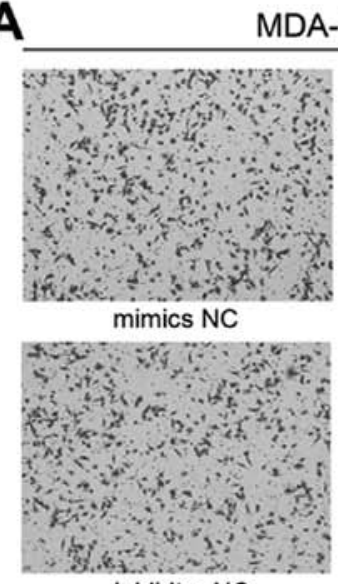

inhibitor NC
MDA-MB-231

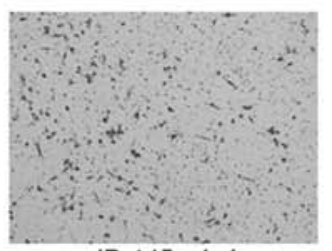

miR-145 mimics

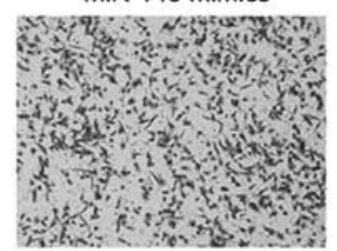

miR-145 inhibitor

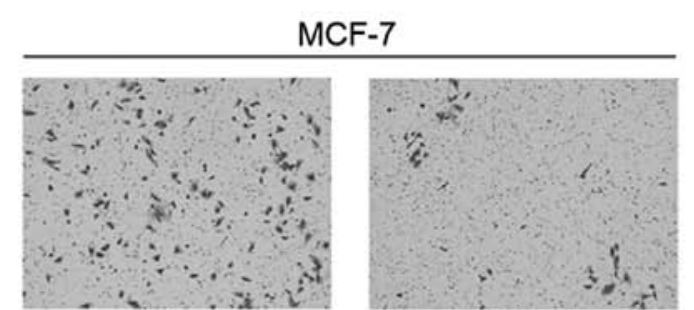

mimics NC

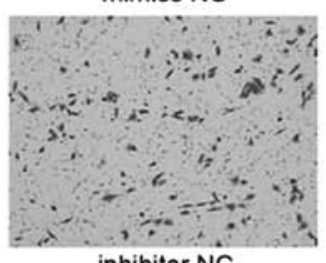

inhibitor NC
miR-145 mimics

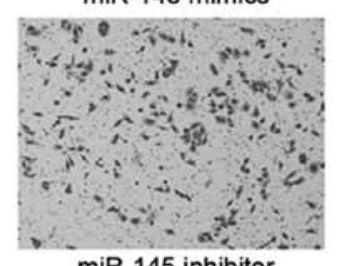

miR-145 inhibitor

B

MDA-MB-231
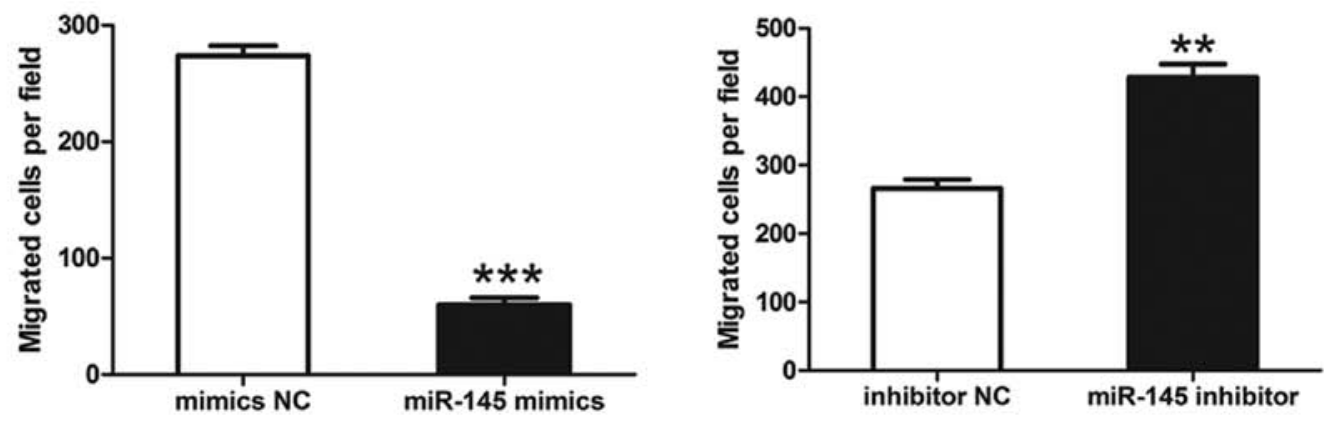

MCF-7
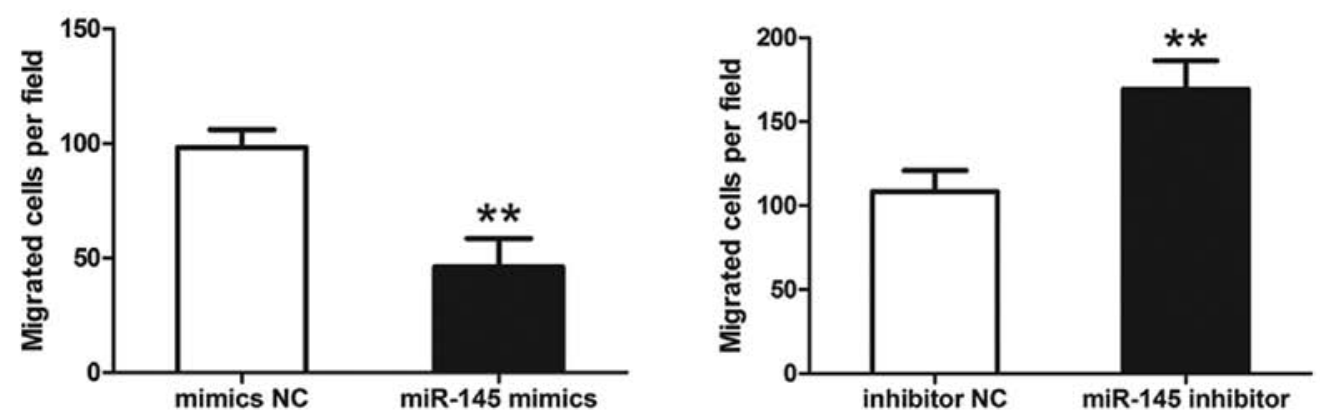

Figure 5. miR-145 influences the invasive ability of breast cancer cells. (A) The invasive ability of breast cancer cells was determined by Transwell invasion assays. Representative images of crystal violet-stained migrated cells were captured $16 \mathrm{~h}$ after invasion of MDA-MB-231 cells (left panels) and $14 \mathrm{~h}$ after invasion of MCF-7 cells (right panels) using an inverted microscope with x100 magnification. (B) Statistical analysis of results in (A). The graph represents the number of migrating MDA-MB-231 cells (B, top panels) and MCF-7 cells (B, bottom panels) shown as means \pm SD. ${ }^{* * *} \mathrm{P}<0.01,{ }^{* * * *} \mathrm{P}<0.001$.

TGF- $\beta 1 \mathrm{mRNA}$ and protein expression. The impact of miR-145 on TGF- $\beta 1$ expression was detected by qRT-PCR assays and western blot analysis. Although we did not find apparent effects on TGF- $\beta 1$ mRNA expression in miR-145 mimics or miR-145 inhibitor transfected cells (Fig. 7B-E), western blot analysis showed that TGF- $\beta 1$ protein expression was significantly decreased or increased in the breast cancer cells after treatment of miR-145 mimics or miR-145 inhibitor (Fig. 7A).

\section{Discussion}

Breast cancer remains the second leading cause of cancerrelated deaths among females (1), and evidence suggests that $20-50 \%$ of patients first diagnosed with primary breast cancer will eventually develop metastatic disease (2). Breast cancer is a heterogeneous disease with varied morphological appearances, molecular features, behavior and response to therapy (12). Unfortunately, current treatment strategies for breast cancer metastasis still largely rely on the use of systemic cytotoxic agents, which usually cause severe side effects, and in many cases have limited long-term success (2). Consequently, developing targeted treatment for breast cancer is of great importance (13). miRNAs are critical regulators of gene expression. Since overexpression of oncogenes or lower expression of tumor suppressor genes will eventually lead to the occurrence of cancer (14), miRNA expression and cancer may be closely linked. 


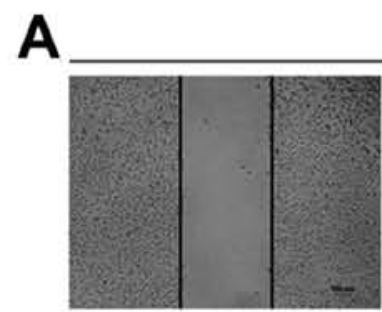

mimics $\mathrm{NCO} \mathrm{h}$

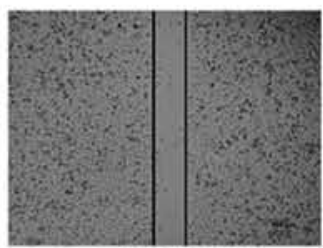

mimics NC $48 \mathrm{~h}$

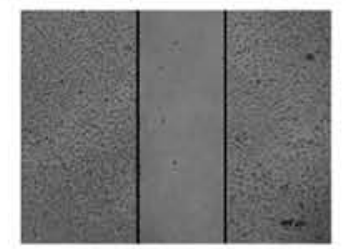

miR-145 mimics $0 \mathrm{~h}$

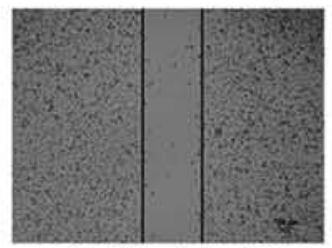

miR-145 mimics $48 \mathrm{~h}$

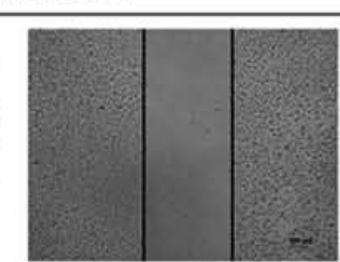

inhibitor $\mathrm{NCO} \mathrm{h}$

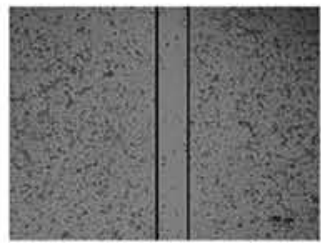

inhibitor NC $48 \mathrm{~h}$

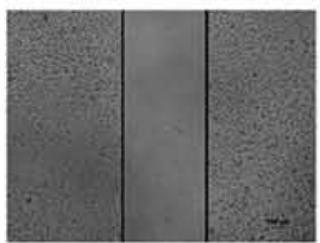

miR-145 inhibitor $0 \mathrm{~h}$

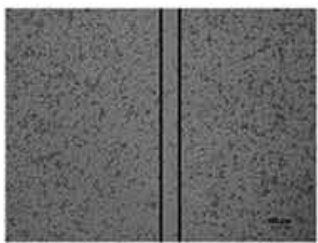

miR-145 inhibitor $48 \mathrm{~h}$

MCF-7

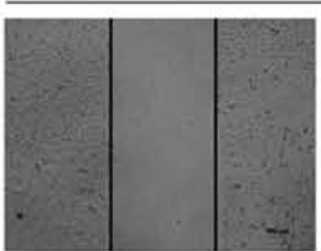

mimics $\mathrm{NCOh}$

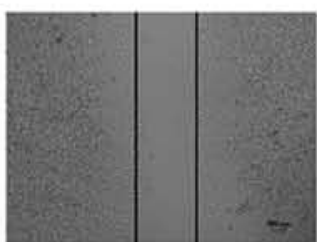

mimics NC $48 \mathrm{~h}$

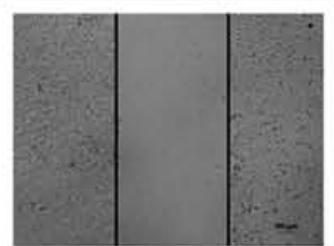

miR-145 mimics $0 \mathrm{~h}$

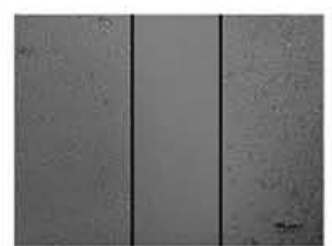

miR-145 mimics $48 \mathrm{~h}$

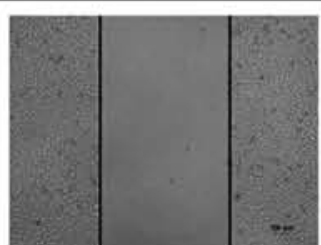

inhibitor $\mathrm{NCO} \mathrm{h}$

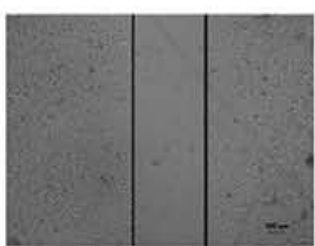

inhibitor NC 48 h

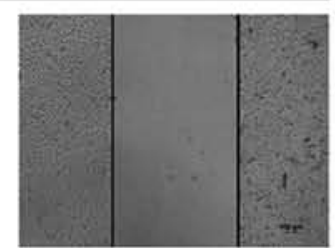

miR-145 inhibitor $0 \mathrm{~h}$

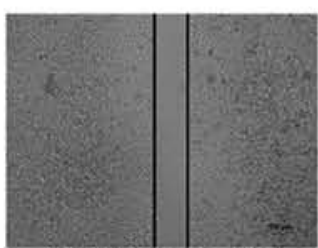

miR-145 inhibitor $48 \mathrm{~h}$

B

MDA-MB-231
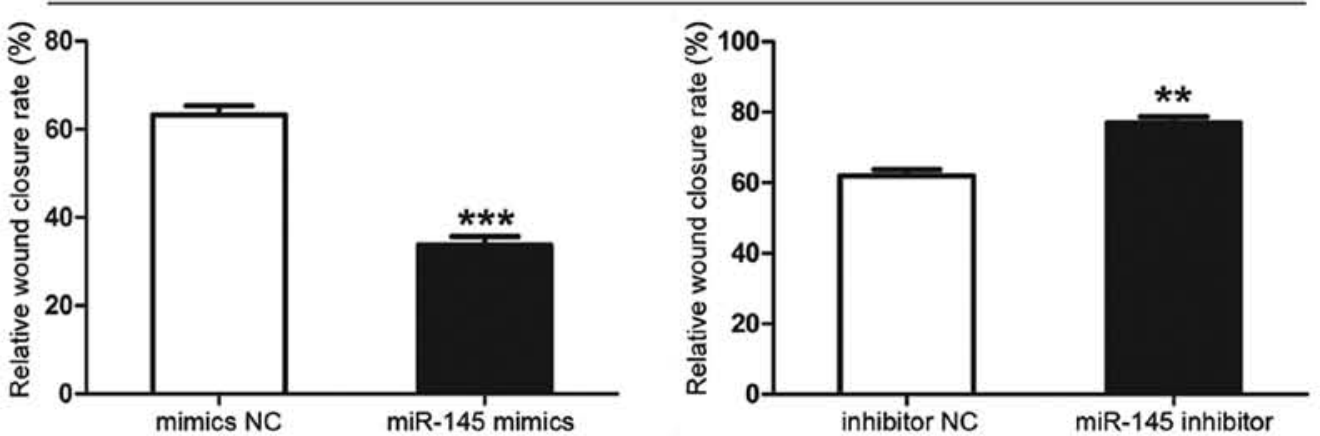

\section{MCF-7}
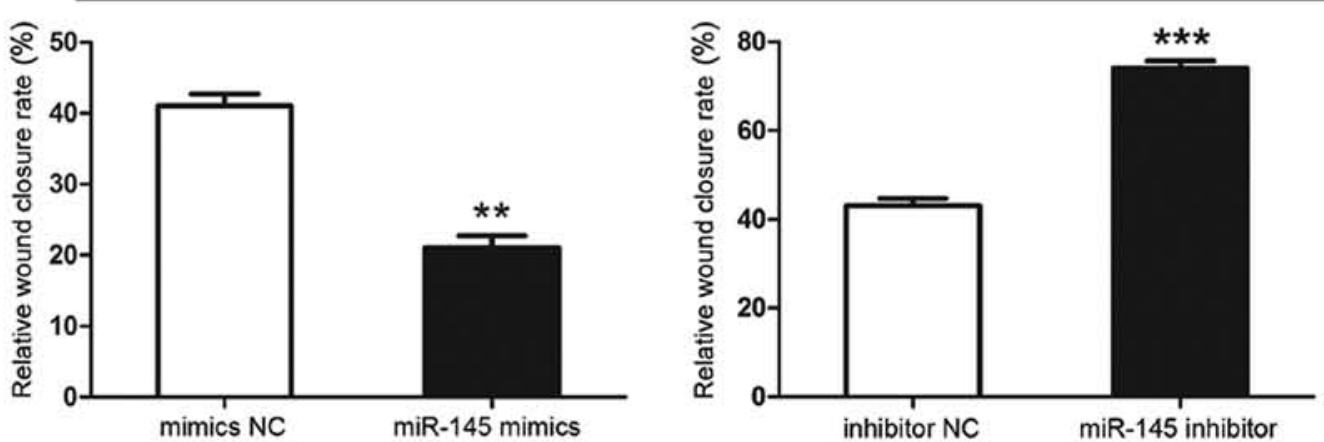

Figure 6. miR-145 decreases migration of breast cancer cells. (A) We used miR-145 mimics, miR-145 inhibitor, mimics NC and inhibitor NC to transfect breast cancer cell lines (MDA-MB-231 and MCF-7). The migratory ability of MDA-MB-231 cells (top panels) and MCF-7 cells (bottom panels) was determined by wound scratch assay $48 \mathrm{~h}$ after wounding. (B) The graph represents the mean wound closure rates \pm SD for MDA-MB-231 cells (top panels) and MCF-7 cells (bottom panels). ${ }^{* *} \mathrm{P}<0.01,{ }^{* * *} \mathrm{P}<0.001$. 
A
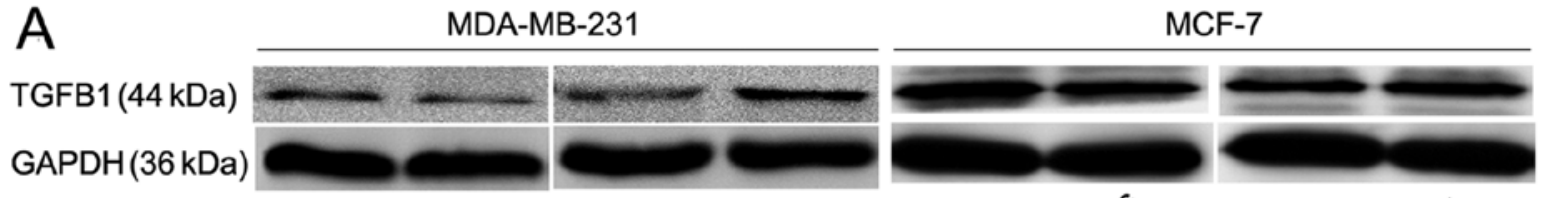

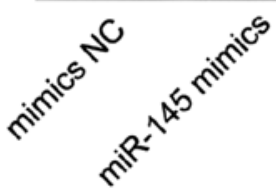

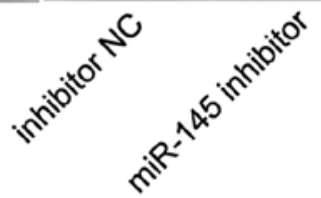

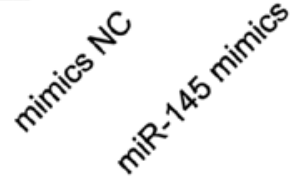

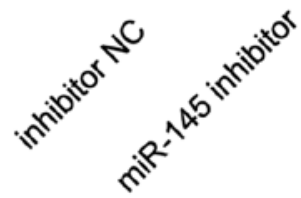

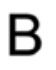

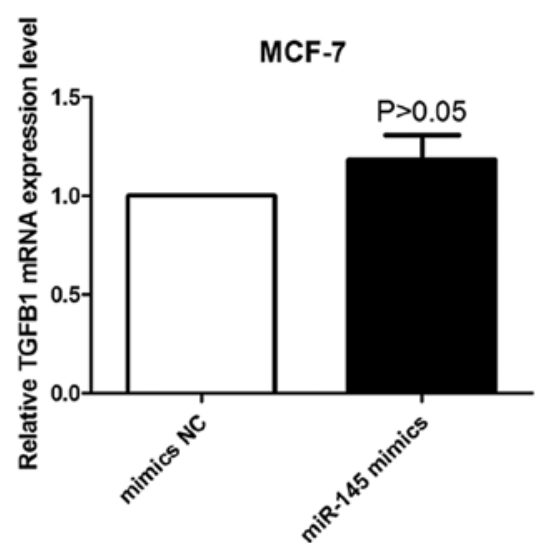

D

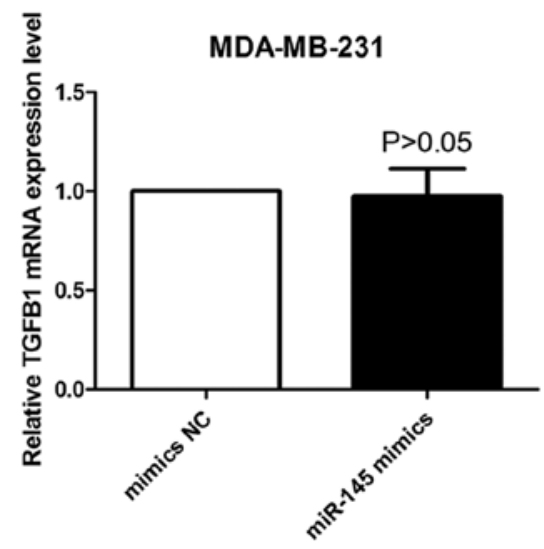

C

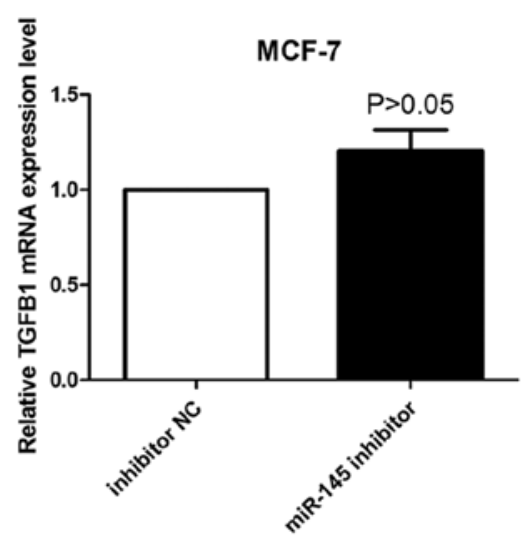

E

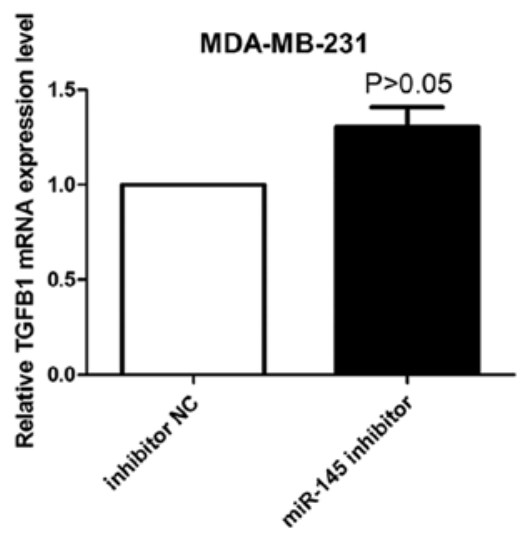

Figure 7. TGF- $\beta 1$ mRNA and protein expression. (A) Representative immunoblot of TGF- $\beta 1$ protein expression in breast cancer cells transfected with miR-145 mimics, miR-145 inhibitor or their negative control. (B, C, D and E) We used qRT-PCR to detect TGF- $\beta 1$ mRNA expression in breast cancer cell lines (MDA-MB-231, MCF-7) at $24 \mathrm{~h}$ after they were transfected with miR-145 mimics or miR-145 inhibitor. The graph represents the relative TGF- $\beta 1 \mathrm{mRNA}$ expression levels in cells transfected with miR-145 mimics (B and D) or miR-145 inhibitor (C and E) compared to their negative controls (mimics NC or inhibitor NC) shown as the mean of $2^{-\Delta \Delta C t}$ values \pm SD.

Since miRNAs were first discovered in the early 1990s, they have been determined to play an increasingly important role in the development and progression of cancer (15). In addition, abnormal miRNA expression can affect cancerrelated processes such as cell proliferation (16), apoptosis, invasion $(16,17)$, and metastasis (17). Regulation of miRNAmediated gene expression is vitally important in many biological processes such as inflammation and neurodegeneration (18). Recent studies have shown that some miRNAs can function as oncogenes or tumor suppressors and regulate cellular proliferation and apoptosis (15), but the role of miRNAs in mediating cancer metastasis remains unexplored $(17,19)$.

Previous studies have shown that some miRNAs can influence the development of breast cancer, including miR-720 (20),
miR-362 (21), miR-125b-1 (22) and miR-493 (23), among others. The role of miR-145 has been widely studied in cancer, and a number of studies have shown abnormal miR-145 expression in a wide variety of tumors, including colon cancer (24), bladder cancer (8), retinoblastoma (25) and colorectal cancer (9). In this study, we used qRT-PCR to detect the expression of miR-145 and found that miR-145 expression was significantly lower in breast cancer tissues compared with corresponding adjacent normal tissues. We thus hypothesized that miR-145 may act as a tumor suppressor. Cell proliferation, invasion and migration were significantly decreased by overexpression of miR-145 in breast cancer cells as shown by MTT assay, colony formation assay, wound healing assay and Transwell assay, whereas low expression of miR-145 significantly enhanced cell growth, invasion and migration. It has been shown that 
miR-145 inhibits cell proliferation, invasion and metastasis by acting as a tumor suppressor in other types of cancer, such as bladder cancer (8), gastric cancer (26), lung cancer (27) and ovarian cancer (28). Previous studies have established that microRNA-145 targets TRIM2 and exerts tumor-suppressing functions in ovarian cancer (29). Thus, these previous studies are consistent with our current data suggesting that miR-145 plays a role as a tumor suppressor in regulating the growth of breast cancer.

From previous studies we know that TGF- $\beta 1$ may play an important role in growth and metastasis of breast cancer cells (11). During tumor development, tumor cells secrete large amounts of active TGF- $\beta 1$ which may promote tumor invasion and metastasis (30). In this study, we demonstrated TGF- $\beta 1$ as a factor mediating the effect of miR-145. The human TGF- $\beta$ family comprises three isoforms: TGF- $\beta 1$, TGF- $\beta 2$ and TGF- $\beta 3$ (31). As the major isoform, TGF- $\beta 1$ has been reported to be overexpressed in many tumors including bladder cancer (32), colorectal cancer (33), cervical neoplasia (34) and pancreatic cancer (35), and associated with tumor transformation and progression (36). Furthermore, as a member of the transforming growth factor family, TGF- $\beta 1$ is involved in enhancing tumor growth, progression and transformation, as well as the invasive and metastatic potential of tumors (36-38).

Finally, we explored the relationship between miR-145 and TGF- $\beta 1$ expression. We used qRT-PCR assays and western blot analysis to assess the impact of miR-145 on TGF- $\beta 1$ expression. We did not find apparent effects on TGF- $\beta 1$ mRNA expression in miR-145 mimics or miR-145 inhibitor transfected cells, but western blot analysis showed that TGF- $\beta 1$ protein expression was significantly decreased or increased in the breast cancer cells after treatment of miR-145 mimics or miR-145 inhibitor. When a miRNA is perfectly complementary to its target, it can specifically degrade the target mRNA (39). We did not find hsa-miR-145 binding site of TGF- $\beta 1$ mRNA, thus we did not find apparent effects on TGF- $\beta 1 \mathrm{mRNA}$ expression. The mechanism of miR-145 inhibiting TGF- $\beta 1$ protein expression requires further study.

In conclusion, in this study, we explore the role of miR-145 in breast cancer development and progression. Our data suggests that miR-145 may act as a tumor-suppressor miRNA in breast cancer through inhibiting proliferation and migration of breast cancer cells. In addition, miR-145 inhibits the protein expression of TGF- $\beta 1$ which may in turn contribute to tumor formation.

\section{Acknowledgements}

This work was supported by the Open Projects of the State Key Laboratory of Immunology of China (grant no. 20150511) and the Science Foundation of Kunshan (grant no. KS1331).

\section{References}

1. Gündüz UR, Gunaldi M, Isiksacan N, Gündüz S, Okuturlar Y and Kocoglu H: A new marker for breast cancer diagnosis, human epididymis protein 4: A preliminary study. Mol Clin Oncol 5: 355-360, 2016.

2. Lu J, Steeg PS, Price JE, Krishnamurthy S, Mani SA, Reuben J, Cristofanilli M, Dontu G, Bidaut L, Valero V, et al: Breast cancer metastasis: Challenges and opportunities. Cancer Res 69: 4951-4953, 2009.
3. Zhang C, Liu K, Li T, Fang J, Ding Y, Sun L, Tu T, Jiang X, Du S, $\mathrm{Hu}$ J, et al: miR-21: A gene of dual regulation in breast cancer. Int J Oncol 48: 161-172, 2016.

4. Nogales-Cadenas R, Cai Y, Lin JR, Zhang Q, Zhang W, Montagna $C$ and Zhang ZD: MicroRNA expression and gene regulation drive breast cancer progression and metastasis in PyMT mice. Breast Cancer Res 18: 75, 2016.

5. Carthew RW and Sontheimer EJ: Origins and mechanisms of miRNAs and siRNAs. Cell 136: 642-655, 2009.

6. Iorio MV, Ferracin M, Liu CG, Veronese A, Spizzo R, Sabbioni S, Magri E, Pedriali M, Fabbri M, Campiglio M, et al: MicroRNA gene expression deregulation in human breast cancer. Cancer Res 65: 7065-7070, 2005.

7. Kloosterman WP and Plasterk RH: The diverse functions of microRNAs in animal development and disease. Dev Cell 11: 441-450, 2006.

8. Kou B, Gao Y, Du C, Shi Q, Xu S, Wang CQ, Wang X, He D and Guo P: miR-145 inhibits invasion of bladder cancer cells by targeting PAK1. Urol Oncol 32: 846-854, 2014.

9. Qin J, Wang F, Jiang H, Xu J, Jiang Y and Wang Z: MicroRNA-145 suppresses cell migration and invasion by targeting paxillin in human colorectal cancer cells. Int J Clin Exp Pathol 8: 1328-1340, 2015.

10. Zhang $\mathrm{Y}$ and Lin Q: MicroRNA-145 inhibits migration and invasion by down-regulating FSCN1 in lung cancer. Int J Clin Exp Med 8: 8794-8802, 2015

11. Park SJ, Kim JG, Kim ND, Yang K, Shim JW and Heo K: Estradiol, TGF- $\beta 1$ and hypoxia promote breast cancer stemness and EMT-mediated breast cancer migration. Oncol Lett 11: 1895-1902, 2016.

12. Rakha EA, Reis-Filho JS, Baehner F, Dabbs DJ, Decker T, Eusebi V, Fox SB, Ichihara S, Jacquemier J, Lakhani SR, et al: Breast cancer prognostic classification in the molecular era: The role of histological grade. Breast Cancer Res 12: 207, 2010.

13. Liu K, Zhang C, Li T, Ding Y, Tu T, Zhou F, Qi W, Chen H and Sun X: Let-7a inhibits growth and migration of breast cancer cells by targeting HMGA1. Int J Oncol 46: 2526-2534, 2015.

14. Lin S and Gregory RI: MicroRNA biogenesis pathways in cancer. Nat Rev Cancer 15: 321-333, 2015.

15. Hwang HW and Mendell JT: MicroRNAs in cell proliferation, cell death, and tumorigenesis. Br J Cancer 94: 776-780, 2006

16. Hiyoshi Y, Kamohara H, Karashima R, Sato N, Imamura Y, Nagai Y, Yoshida N, Toyama E, Hayashi N, Watanabe M, et al: MicroRNA-21 regulates the proliferation and invasion in esophageal squamous cell carcinoma. Clin Cancer Res 15: 1915-1922, 2009.

17. Ma L, Teruya-Feldstein J and Weinberg RA: Tumour invasion and metastasis initiated by microRNA-10b in breast cancer. Nature 449: 682-688, 2007.

18. Vaknin-Dembinsky A, Charbit H, Brill L, Abramsky O, Gur-Wahnon D, Ben-Dov IZ and Lavon I: Circulating microRNAs as biomarkers for rituximab therapy, in neuromyelitis optica (NMO). J Neuroinflammation 13: 179, 2016.

19. Li Y, Deng X, Zeng X and Peng X: The role of miR-148a in cancer. J Cancer 7: 1233-1241, 2016.

20. Li LZ, Zhang CZ, Liu LL, Yi C, Lu SX, Zhou X, Zhang ZJ, Peng YH, Yang YZ and Yun JP: miR-720 inhibits tumor invasion and migration in breast cancer by targeting TWIST1. Carcinogenesis 35: 469-478, 2014.

21. Ni F, Gui Z, Guo Q, Hu Z, Wang X, Chen D and Wang S: Downregulation of miR-362-5p inhibits proliferation, migration and invasion of human breast cancer MCF7 cells. Oncol Lett 11: 1155-1160, 2016.

22. Cisneros-Soberanis F, Andonegui MA and Herrera LA: miR-125b-1 is repressed by histone modifications in breast cancer cell lines. Springerplus 5: 959, 2016.

23. Zhao L, Feng X, Song X, Zhou H, Zhao Y, Cheng L and Jia L: miR-493-5p attenuates the invasiveness and tumorigenicity in human breast cancer by targeting FUT4. Oncol Rep 36: 1007-1015, 2016

24. Li C, Xu N, Li YQ, Wang Y and Zhu ZT: Inhibition of SW620 human colon cancer cells by upregulating miRNA-145. World J Gastroenterol 22: 2771-2778, 2016.

25. Sun Z, Zhang A, Jiang T, Du Z, Che C and Wang F: MiR-145 suppressed human retinoblastoma cell proliferation and invasion by targeting ADAM19. Int J Clin Exp Pathol 8: 14521-14527, 2015.

26. Jiang SB, He XJ, Xia YJ, Hu WJ, Luo JG, Zhang J and Tao HQ: MicroRNA-145-5p inhibits gastric cancer invasiveness through targeting N-cadherin and ZEB2 to suppress epithelialmesenchymal transition. Onco Targets Ther 9: 2305-2315, 2016. 
27. Li Y, Li Y, Liu J, Fan Y, Li X, Dong M, Liu H and Chen J: Expression levels of microRNA-145 and microRNA-10b are associated with metastasis in non-small cell lung cancer. Cancer Biol Ther 17: 272-279, 2016.

28. Dong R, Liu X, Zhang Q, Jiang Z, Li Y, Wei Y, Li Y, Yang Q, Liu J, Wei JJ, et al: miR-145 inhibits tumor growth and metastasis by targeting metadherin in high-grade serous ovarian carcinoma. Oncotarget 5: 10816-10829, 2014.

29. Chen X, Dong C, Law PT, Chan MT, Su Z, Wang S, Wu WK and Xu H: MicroRNA-145 targets TRIM2 and exerts tumorsuppressing functions in epithelial ovarian cancer. Gynecol Oncol 139: 513-519, 2015.

30. Ding MJ, Su KE, Cui GZ, Yang WH, Chen L, Yang M, Liu YQ and Dai DL: Association between transforming growth factor- $\beta 1$ expression and the clinical features of triple negative breast cancer. Oncol Lett 11: 4040-4044, 2016.

31. Zheng W: Genetic polymorphisms in the transforming growth factor-beta signaling pathways and breast cancer risk and survival. Methods Mol Biol 472: 265-277, 2009.

32. Eder IE, Stenzl A, Hobisch A, Cronauer MV, Bartsch G and Klocker H: Transforming growth factors-beta 1 and beta 2 in serum and urine from patients with bladder carcinoma. J Urol 156: 953-957, 1996.

33. Tsushima H, Kawata S, Tamura S, Ito N, Shirai Y, Kiso S, Imai Y, Shimomukai H, Nomura Y, Matsuda Y, et al: High levels of transforming growth factor beta 1 in patients with colorectal cancer: Association with disease progression. Gastroenterology 110: 375-382, 1996.
34. Comerci JT Jr, Runowicz CD, Flanders KC, De Victoria C, Fields AL, Kadish AS and Goldberg GL: Altered expression of transforming growth factor-beta 1 in cervical neoplasia as an early biomarker in carcinogenesis of the uterine cervix. Cancer 77: 1107-1114, 1996.

35. Friess H, Yamanaka Y, Büchler M, Ebert M, Beger HG, Gold LI and Korc M: Enhanced expression of transforming growth factor beta isoforms in pancreatic cancer correlates with decreased survival. Gastroenterology 105: 1846-1856, 1993.

36. Sheen-Chen SM, Chen HS, Sheen CW, Eng HL and Chen WJ: Serum levels of transforming growth factor betal in patients with breast cancer. Arch Surg 136: 937-940, 2001.

37. Chen JY, Liu JH, Wu HD, Lin KH, Chang KC and Liou YM Transforming growth factor- $\beta 1$ T869C gene polymorphism is associated with acquired sick sinus syndrome via linking a higher serum protein level. PLoS One 11: e0158676, 2016.

38. Kelly RJ and Morris JC: Transforming growth factor-beta: A target for cancer therapy. J Immunotoxicol 7: 15-26, 2010.

39. Hornstein E, Mansfield JH, Yekta S, Hu JK, Harfe BD, McManus MT, Baskerville S, Bartel DP and Tabin CJ: The microRNA miR-196 acts upstream of Hoxb8 and Shh in limb development. Nature 438: 671-674, 2005. 